\title{
Dose-dependent effects of docosahexaenoic acid-rich fish oil on erythrocyte docosahexaenoic acid and blood lipid levels
}

\author{
Catherine M. Milte ${ }^{1,2}$, Alison M. Coates ${ }^{1}$, Jonathan D. Buckley ${ }^{1}$, Alison M. Hill ${ }^{1,2}$ and Peter R. C. Howe ${ }^{1,2 *}$ \\ ${ }^{1}$ Nutritional Physiology Research Centre and ATN Centre for Metabolic Fitness, University of South Australia, Adelaide, South \\ Australia 5001, Australia \\ ${ }^{2}$ School of Molecular and Biomedical Sciences, University of Adelaide, South Australia 5005, Australia
}

(Received 23 April 2007 - Revised 21 September 2007 - Accepted 24 September 2007 - First published online 31 October 2007)

Consumption of long-chain $n$-3 PUFA, particularly DHA, has been shown to improve cardiovascular risk factors but the intake required to achieve benefits is unclear. We sought to determine the relationship between DHA intake, increases in erythrocyte DHA content and changes in blood lipids. A total of sixty-seven subjects (thirty-six male, thirty-one female, mean age 53 years) with fasting serum $\mathrm{TAG} \geq 1.1 \mathrm{mmol} / \mathrm{l}$ and BMI $>25 \mathrm{~kg} / \mathrm{m}^{2}$ completed a 12-week, randomized, double-blind, placebo-controlled parallel intervention. Subjects consumed 2, 4 or $6 \mathrm{~g} / \mathrm{d}$ of DHA-rich fish oil (26\% DHA, $6 \%$ EPA) or a placebo (Sunola oil). Fasting blood lipid concentrations and fatty acid profiles in erythrocyte membranes were assessed at baseline and after 6 and 12 weeks. For every $1 \mathrm{~g} / \mathrm{d}$ increase in DHA intake, there was a $23 \%$ reduction in TAG (mean baseline concentration 1.9 (SEM 0.1) mmol/1), $4.4 \%$ increase in HDL-cholesterol and 7.1\% increase in LDL-cholesterol. Erythrocyte DHA content increased in proportion to the dose of DHA consumed $(r 0.72, P<0.001)$ and the increase after 12 weeks was linearly related to reductions in TAG $(r-0.38, P<0.01)$ and increases in total cholesterol $(r 0.39, P<0.01)$, LDL-cholesterol $(r 0.33, P<0.01)$ and HDL-cholesterol $(r 0.30, P=0.02)$. The close association between incorporation of DHA in erythrocytes and its effects on serum lipids highlights the importance of erythrocyte DHA as an indicator of cardiovascular health status.

Lipids: $n$-3 PUFA: Docosahexaenoic acid

Fish oil supplementation increases the relative proportion of the long-chain (LC) $n$-3 PUFA, EPA and DHA, in erythrocyte membranes ${ }^{(1)}$. DHA, in particular, is incorporated on the inside of the erythrocyte membrane and is present for the life of the cell ${ }^{(1,2)}$. This provides a readily assessable marker of long-term accumulation and potential bioavailability in other tissues $^{(3)}$. Increased incorporation of LC $n-3$ PUFA in erythrocyte membranes is associated with reduced CVD morbidity and mortality ${ }^{(4)}$. This relationship forms the basis of the Omega-3 Index ${ }^{(4)}$, a concept promoted as a relatively simple means of predicting the likelihood of CVD outcomes. However, it may also be possible to relate erythrocyte LC $n-3$ PUFA to CVD risk factors rather than morbidity and mortality, thereby allowing for the prediction of improvement in risk factors resulting from dietary intervention.

A high TAG level in fasting blood is an independent risk factor for $\mathrm{CVD}^{(5,6)}$. LC $n-3$ PUFA consumption lowers blood TAG levels in healthy subjects ${ }^{(7-11)}$ but the optimal dose for TAG reduction is not clear. While the American Heart Association recommends consuming 2-4 g $n-3$ PUFA/d for TAG reduction in individuals with hypertriacylglycerolae$\mathrm{mia}^{(12)}$, a recent study reported a $23 \%$ reduction in fasting TAG in normolipidaemics with only $0.94 \mathrm{~g} \mathrm{DHA} / \mathrm{d}$, indicating that lower doses of fish oil may also be effective for TAG reduction ${ }^{(10)}$. The TAG-lowering effect of fish oil has been variously attributed to $\mathrm{EPA}^{(13)}$ or equally to EPA and DHA $^{(11)}$. Numerous studies with DHA-rich oil have shown reductions in $\operatorname{TAG}^{(9,10,14,15)}$, and the addition of EPA in a DHA-rich supplement was previously found to have no additional effect on TAG-lowering ${ }^{(16)}$. However, there have been few well-designed studies aimed at establishing a dose-response relationship between DHA intake and TAG reduction. Previous studies used small sample sizes in their intervention ${ }^{(17-20)}$, dietary restriction ${ }^{(18)}$ or participants with extreme hypertriacylglycerolaemia (up to $13.45 \mathrm{mmol} / \mathrm{l})^{(17)}$.

The purpose of the present study was to establish a doseresponse relationship between moderate levels of DHA-rich fish oil supplementation and changes in both erythrocyte DHA content and blood lipids.

\section{Methods}

A randomized, double-blind, placebo-controlled, parallel design dose-response supplementation trial of 12 weeks duration was undertaken. The study was approved by the Human Research Ethics Committees of the University of Adelaide and 
the University of South Australia (Adelaide, Australia) and conducted according to Good Clinical Research Practice Guidelines. Written informed consent was obtained from all participants prior to commencement.

\section{Subjects}

Seventy-five non-smoking volunteers with a BMI $>25 \mathrm{~kg} / \mathrm{m}^{2}$ and fasting serum $\mathrm{TAG} \geq 1.1 \mathrm{mmol} / \mathrm{l}$ were recruited for the study. Participants taking lipid-lowering, blood-thinning or antihypertensive medication, fish oil supplements or consuming more than one serving of fish per week were excluded.

\section{Study design}

Subjects were block-matched into four groups which were stratified according to fasting serum TAG concentration. The groups were then randomized to consume six $1 \mathrm{~g}$ oil capsules/d comprising either $0,2,4$ or $6 \times 1 \mathrm{~g}$ capsules of DHA-rich fish oil containing $26 \%$ DHA and 6\% EPA (NuMega Ingredients, Victoria, Australia) with the balance of the capsules made up of $1 \mathrm{~g}$ Sunola oil capsules (NuMega Ingredients). The 2,4 and $6 \mathrm{~g} / \mathrm{d}$ doses provided $0.52,1.04$ and $1.56 \mathrm{~g} \mathrm{DHA} / \mathrm{d}$, respectively. Subjects visited the research clinic on two consecutive mornings at baseline, week 6 and week 12 after an overnight $(10-12 \mathrm{~h})$ fast. Height and weight were measured and blood was collected by venepuncture on each occasion.

\section{Assessment of erythrocyte fatty acid profiles}

The relative proportions of LC $n$-3 PUFA in erythrocytes were determined as described previously ${ }^{(21)}$. Briefly, blood samples were collected in EDTA tubes and erythrocytes were isolated within $2 \mathrm{~h}$ by centrifugation, washed in isotonic saline and stored at $-80^{\circ} \mathrm{C}$. They were subsequently thawed, lysed in hypotonic Tris/EDTA buffered at $\mathrm{pH} 7.4$ then centrifuged at $50000 \mathrm{~g}$ for $30 \mathrm{~min}$ in a Beckman L80 ultracentrifuge. The resultant pellet was gently resuspended in the buffer and the fatty acids were extracted, and assayed by flame-ionization GC (model GC-20A; Shimazdu, Kyoto, Japan). Individual fatty acids were identified by comparison with known standards (NuChek Prep Inc., Elysian, MN, USA).

\section{Assessment of fasting serum lipids}

Blood samples were also collected in $8 \mathrm{ml}$ serum tubes for determination of TAG, total cholesterol and HDL-cholesterol (HDL-C) levels using a spectrophotometric autoanalyser (Konelab, Model $20 \times \mathrm{Ti}$; Thermo Electron, Waltham, MA, USA) with the manufacturer's assay kits, quality controls and reagents. LDL-cholesterol (LDL-C) was calculated using the Friedewald Equation ${ }^{(22)}$. Lipid concentrations were averaged from the values for the two blood samples taken at consecutive clinic visits.

\section{Statistical analysis}

Baseline markers were compared between groups using oneway ANOVA. CVD risk biomarkers and the DHA content of erythrocytes were compared between time-points by repeated measures ANOVA using Statistica for Windows version 5.1 (StatSoft Inc., Tulsa, OK, USA). The relationship between fish oil dose, DHA dose, or changes in erythrocyte LC $n$-3 PUFA content and changes in blood lipids (expressed as a percentage of baseline value) were analysed by linear regression. All data are expressed as mean with their standard errors. The level of significance was set at $P<0 \cdot 05$.

\section{Results}

Seventy-five volunteers commenced the study and sixty-seven completed. Eight withdrew due to personal time constraints. There were no significant differences in age, BMI or blood lipids between the four dosing groups at baseline (Table 1). BMI was not significantly altered over the 12 weeks with any of the treatments.

\section{Increases in erythrocyte n-3 PUFA}

There was no difference between treatment groups in either DHA or EPA contents of erythrocytes at baseline. Fish oil supplementation progressively increased the levels of EPA and DHA in erythrocyte membranes over 12 weeks (Fig. 1). The proportion of EPA + DHA in erythrocytes increased by up to $80 \%$ over 12 weeks. Most of this increase was attributable to DHA which rose by $78 \%$ with the $6 \mathrm{~g} / \mathrm{d}$ of DHA-rich fish oil. There was a strong linear relationship between the fish oil dose and the changes in DHA incorporation by week $6(r 0.71, P<0.001)$ and week $12(r \quad 0.72, P<0.001)$. A weaker relationship was found between fish oil dose and change in EPA incorporation at both week 6 ( $r$ 0.49, $P<0.001)$ and week $12(r 0.58, P<0.001)$.

\section{Changes in fasting serum lipids}

Fish oil supplementation was associated with changes in fasting serum lipids (Fig. 2). A significant group $\times$ time interaction was demonstrated for TAG, total cholesterol and LDL-C. There was no significant group $\times$ time interaction for HDL-C, nor was there any significant time effect when the HDL-C data were pooled. TAG did not change significantly with the 0 and $2 \mathrm{~g} / \mathrm{d}$ doses, but was reduced significantly after 6 weeks of supplementation with 4 and $6 \mathrm{~g} / \mathrm{d}$ and remained low after 12 weeks (Table 1). LDL-C was significantly increased at weeks 6 and 12 only with the $4 \mathrm{~g} / \mathrm{d}$ dose. HDL-C and total cholesterol did not change significantly from baseline with any dose. The change in TAG at weeks 6 and 12 was inversely related to baseline TAG concentrations (week 6, $r-0.69, P<0.001$; week 12, $r-0.44, P<0.001$ ). There were also significant linear relationships between DHA intake and changes in fasting blood lipids after 12 weeks of supplementation (Fig. 2).

The changes in blood lipid concentrations were also linearly related to changes in EPA and DHA incorporation into erythrocytes (Table 2). The reduction in TAG at 12 weeks correlated more strongly with changes in DHA $(r-0.38)$ than with changes in either EPA $(r-0.26)$ or EPA + DHA $(r-0.32)$ after 12 weeks. There was also a relationship between the increase in erythrocyte DHA after 6 weeks and TAG reduction after 12 weeks $(r-0.44, P<0.001)$. 
Table 1. Characteristics of the subjects

(Mean values with their standard errors)

\begin{tabular}{|c|c|c|c|c|c|c|c|c|}
\hline & \multicolumn{8}{|c|}{ Fish oil $(g / d)$} \\
\hline & \multicolumn{2}{|c|}{0} & \multicolumn{2}{|c|}{2} & \multicolumn{2}{|c|}{4} & \multicolumn{2}{|c|}{6} \\
\hline & Mean & SEM & Mean & SEM & Mean & SEM & Mean & SEM \\
\hline Age (years) & 53 & $2 \cdot 3$ & 53 & $2 \cdot 0$ & 53 & $1 \cdot 3$ & 52 & $2 \cdot 1$ \\
\hline$n$ & \multicolumn{2}{|c|}{19} & \multicolumn{2}{|c|}{17} & \multicolumn{2}{|c|}{20} & \multicolumn{2}{|c|}{19} \\
\hline No. of males/females & \multicolumn{2}{|c|}{$12 / 7$} & \multicolumn{2}{|c|}{$8 / 9$} & \multicolumn{2}{|c|}{$11 / 9$} & \multicolumn{2}{|c|}{$11 / 8$} \\
\hline BMI $\left(\mathrm{kg} / \mathrm{m}^{2}\right)$ & 31 & 1.0 & 32 & $1 \cdot 1$ & 32 & $1 \cdot 2$ & 32 & 1.3 \\
\hline \multicolumn{9}{|l|}{ TAG $(\mathrm{mmol} / \mathrm{l})$} \\
\hline Week 0 & $1 \cdot 7$ & 0.2 & $1 \cdot 7$ & 0.1 & $2 \cdot 0$ & 0.3 & $2 \cdot 0$ & 0.1 \\
\hline Week 6 & $1 \cdot 7$ & 0.2 & 1.6 & 0.2 & $1 \cdot 6^{*}$ & 0.2 & $1 \cdot 5^{\star}$ & 0.1 \\
\hline Week 12 & $1 \cdot 7$ & 0.2 & $1 \cdot 3$ & 0.1 & $1 \cdot 7^{\star}$ & 0.3 & $1.4^{\star}$ & 0.1 \\
\hline \multicolumn{9}{|l|}{$\mathrm{TC}(\mathrm{mmol} / \mathrm{l})$} \\
\hline Week 0 & $6 \cdot 6$ & 0.2 & $6 \cdot 5$ & 0.2 & $6 \cdot 7$ & 0.3 & $6 \cdot 1$ & 0.2 \\
\hline Week 6 & $6 \cdot 6$ & 0.2 & $6 \cdot 8$ & 0.2 & $7 \cdot 0$ & 0.3 & $6 \cdot 2$ & 0.2 \\
\hline Week 12 & $6 \cdot 4$ & 0.3 & $6 \cdot 2$ & 0.2 & $7 \cdot 0$ & 0.3 & $6 \cdot 4$ & 0.2 \\
\hline \multicolumn{9}{|l|}{ LDL-C (mmol/l) } \\
\hline Week 0 & $4 \cdot 3$ & 0.2 & $4 \cdot 4$ & 0.2 & $4 \cdot 1$ & 0.2 & $3 \cdot 7$ & 0.2 \\
\hline Week 6 & $4 \cdot 3$ & 0.2 & $4 \cdot 3$ & 0.2 & $4 \cdot 5^{\star}$ & 0.3 & $4 \cdot 0$ & 0.2 \\
\hline Week 12 & $4 \cdot 0$ & 0.3 & $4 \cdot 0$ & 0.3 & $4 \cdot 6^{*}$ & 0.3 & $4 \cdot 1$ & 0.2 \\
\hline \multicolumn{9}{|l|}{ HDL-C (mmol/l) } \\
\hline Week 0 & 1.5 & $0 \cdot 1$ & $1 \cdot 5$ & 0.1 & $1 \cdot 7$ & 0.1 & 1.4 & 0.1 \\
\hline Week 6 & 1.5 & 0.1 & 1.5 & 0.1 & $1 \cdot 7$ & 0.1 & 1.5 & 0.1 \\
\hline Week 12 & 1.5 & 0.1 & $1 \cdot 5$ & 0.1 & $1 \cdot 7$ & 0.1 & 1.6 & 0.1 \\
\hline
\end{tabular}

HDL-C, fasting serum HDL-cholesterol concentration; LDL-C, fasting serum LDL-cholesterol concentration; TC, fasting serum total cholesterol concentration.

${ }^{*}$ Mean values were significantly different from those for $0 \mathrm{~g}(P<0.05)$.

\section{Discussion}

The results of the present study demonstrate that fasting blood lipid levels can be modified in a dose-dependent fashion by moderate levels of supplementation with DHA-rich fish oil. Moreover, beneficial reductions in TAG correlate closely with early rises in erythrocyte DHA levels. LC $n$-3 PUFA supplementation has been reported to lower TAG concentrations by multiple mechanisms, including by increasing lipoprotein lipase activity and chylomicron clearance ${ }^{(23)}$, inhibiting hepatic synthesis, increasing fatty acid oxidation and decreasing VLDLcholesterol secretion ${ }^{(24)}$. In the present study, we observed a dose-related reduction in fasting serum TAG. The greatest reduction in TAG $(26 \%)$ occurred after 12 weeks in the group receiving $6 \mathrm{~g} / \mathrm{d}$ of fish oil, equivalent to $1.56 \mathrm{~g} \mathrm{DHA} / \mathrm{d}$. Previous studies have shown similar reductions in TAG although the dose of DHA used varied greatly $(0.94 \text { to }>4 \mathrm{~g} / \mathrm{d})^{(9-11)}$.

Previous attempts to define a dose-response between LC $n-3$ PUFA consumption and improvements in CVD biomarkers include multiple dose studies using smaller groups ${ }^{(17-20,25)}$ or
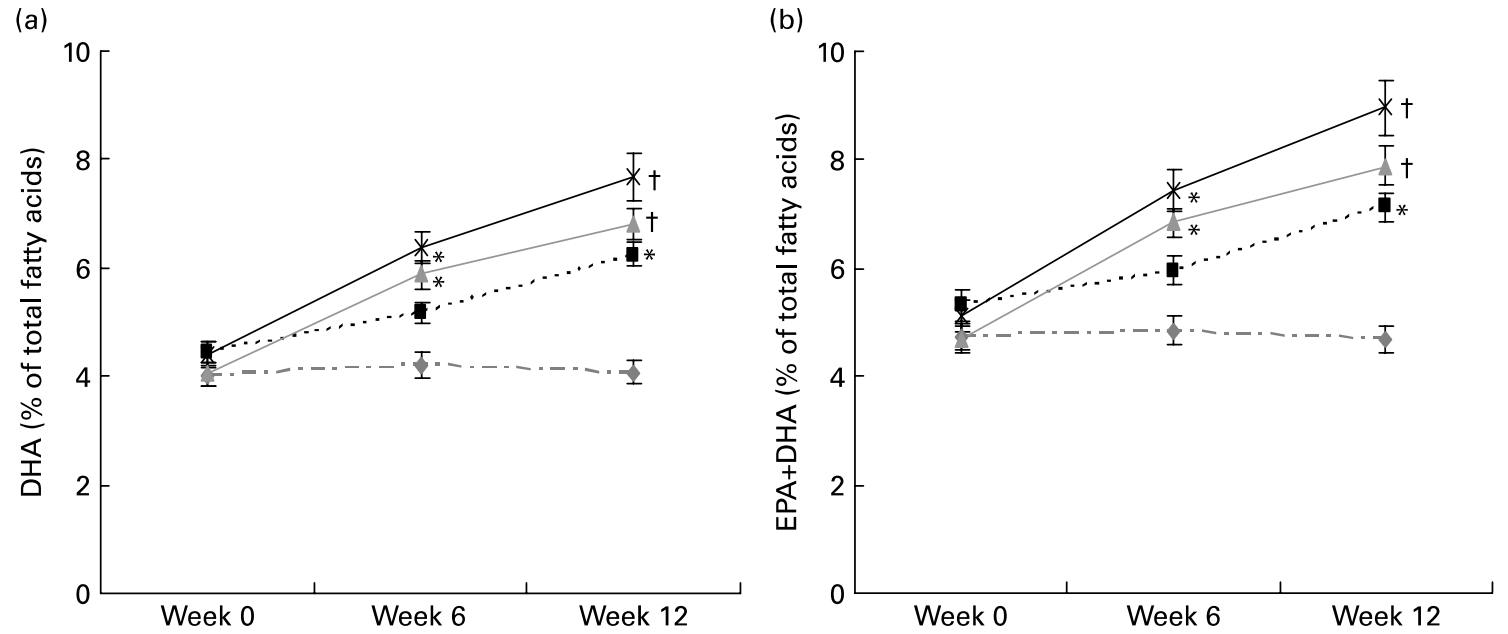

Fig. 1. Dose-dependent effect of DHA-rich fish oil $(\diamond, 0 ; \mathbf{\square}, 2 ; \Delta, 4 ; \times, 6 \mathrm{~g} / \mathrm{d}$ ) for 12 weeks on DHA (a) and EPA + DHA (b) content of erythrocytes (\% of total fatty acids). Values are means with their standard errors depicted by vertical bars. Mean values were significantly different from those of week $0:{ }^{\star} P<0.05$. Mean values were significantly different from those of weeks 0 and $6: \uparrow P<0.05$. 
(a)

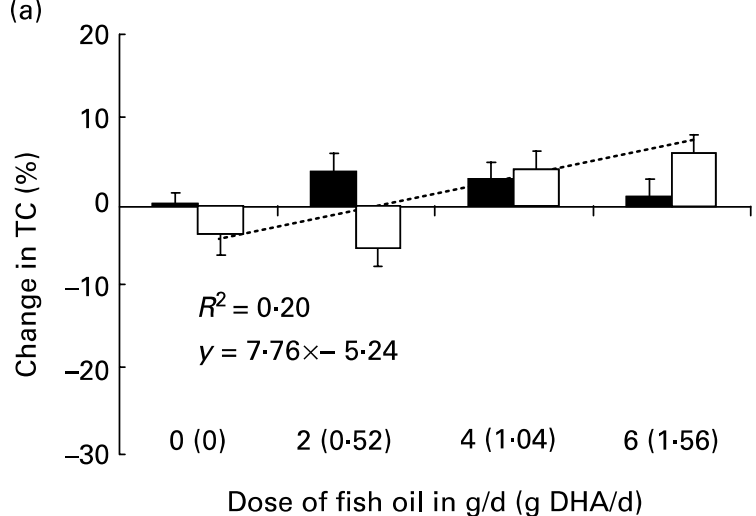

(c)

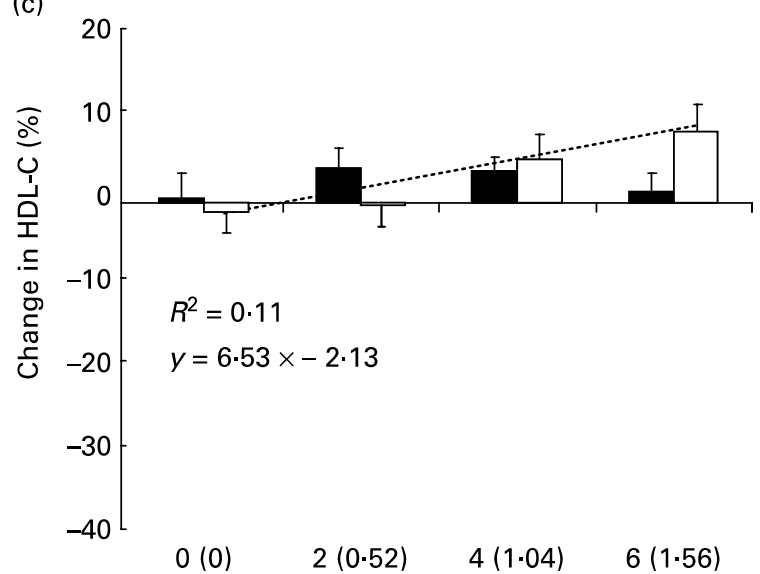

(b)

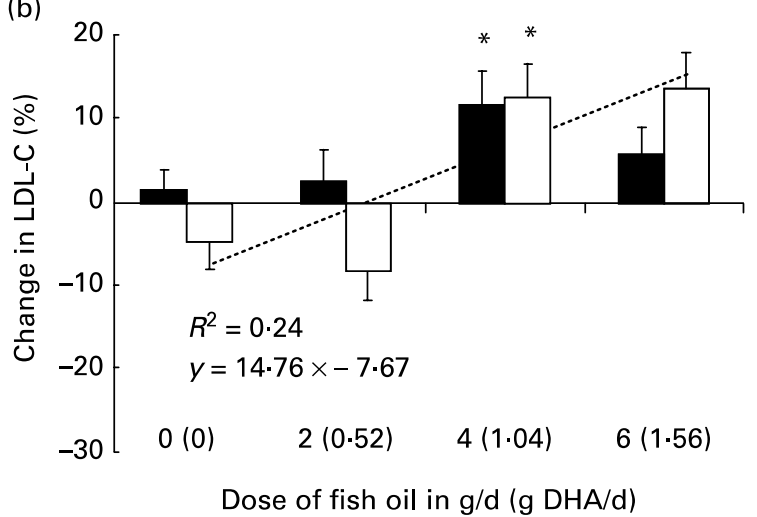

(d)

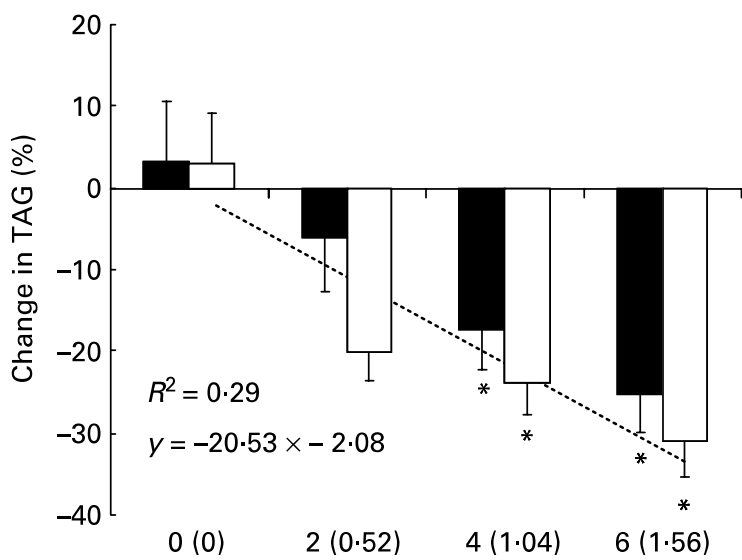

Dose of fish oil in g/d (g DHA/d)

Dose of fish oil in g/d (g DHA/d)

Fig. 2. Percentage changes in fasting serum lipid concentration from baseline after $6(\square)$ and 12 ( $\square$ ) weeks of fish oil (DHA) supplementation. Mean values were significantly different from those of $0 \mathrm{~g} / \mathrm{d}$ : ${ }^{\star} P<0.05$. - linear regressions between dose of fish oil (DHA) and changes in lipids after 12 weeks. HDL-C, fasting serum HDL-cholesterol concentration; LDL-C, fasting serum LDL-cholesterol concentration; TC, fasting serum total cholesterol concentration.

subjects with severe hypertriacylglycerolaemia ${ }^{(17)}$. Moreover, they have not focused on the role of DHA. In the present study, LC $n$-3 PUFA bioavailability was manipulated by low $(2-6 \mathrm{~g} / \mathrm{d})$ doses of DHA-rich fish oil, yielding $0.52-1.56 \mathrm{~g}$ DHA/d. Similar intakes could be achieved by eating one serving of fatty fish such as salmon, mackerel or sardines per day ${ }^{(26)}$. To reduce the risk of mortality from CVD, a daily intake of $250 \mathrm{mg}$ $\mathrm{EPA}+\mathrm{DHA}$ is recommended for healthy individuals and $1 \mathrm{~g}$

Table 2. Correlations between changes in serum lipids from baseline to week $12(\mathrm{mmol} / \mathrm{l})$ and changes in incorporation of DHA and EPA into erythrocytes

\begin{tabular}{|c|c|c|c|c|c|c|}
\hline & \multicolumn{2}{|c|}{$\begin{array}{l}\text { Change in eryth- } \\
\text { rocyte DHA } \\
\text { (\% of total fatty } \\
\text { acids) }\end{array}$} & \multicolumn{2}{|c|}{$\begin{array}{l}\text { Change in eryth- } \\
\text { rocyte EPA } \\
\text { (\% of total fatty } \\
\text { acids) }\end{array}$} & \multicolumn{2}{|c|}{$\begin{array}{c}\text { Change in eryth- } \\
\text { rocyte EPA + } \\
\text { DHA (\% of total } \\
\text { fatty acids) }\end{array}$} \\
\hline & $r$ & $P$ & $r$ & $P$ & $r$ & $P$ \\
\hline $\mathrm{TC}$ & 0.39 & 0.001 & 0.41 & 0.001 & 0.41 & 0.001 \\
\hline LDL-C & 0.33 & 0.008 & 0.35 & 0.005 & 0.31 & 0.014 \\
\hline HDL-C & 0.30 & 0.016 & 0.30 & 0.018 & 0.34 & 0.006 \\
\hline TAG & -0.38 & 0.002 & -0.26 & 0.038 & -0.32 & 0.008 \\
\hline
\end{tabular}

HDL-C, HDL-cholesterol; LDL-C, LDL-cholesterol; TC, total cholesterol. for those with $\mathrm{CVD}^{(27)}$. Harris \& von Schacky ${ }^{(4)}$ previously showed that the latter $(1 \mathrm{~g} / \mathrm{d})$ was able to increase erythrocyte $\mathrm{EPA}+$ DHA levels above $8 \%$, their target value for cardioprotection. An intake of EPA + DHA of $1.99 \mathrm{~g} / \mathrm{d}$ in the present study was able to increase erythrocyte EPA + DHA levels to above $8 \%$, possibly providing increased cardioprotection.

Erythrocyte EPA + DHA content at baseline in the present study was $<5 \%$ of total fatty acids (Fig. 1), which is consistent with previous observations in Australian adults ${ }^{(21,28)}$. Consuming the 2, 4 and $6 \mathrm{~g} / \mathrm{d}$ doses of DHA-rich fish oil for 12 weeks increased the proportion of EPA + DHA in erythrocytes to $7.1,7.9$ and $9.0 \%$ of total fatty acids, respectively. Fig. 1 indicates that consumption for a longer duration approaching the lifespan of erythrocytes (4 months) would result in some degree of saturation of erythrocyte membranes so that the linear relationship between dose of fish oil and level of EPA and DHA in erythrocytes would be weaker. The difference between doses was more apparent at 6 weeks than at 12 weeks, suggesting that a maximum level of incorporation would ultimately be reached. The intermediate dose $(1.35 \mathrm{~g} / \mathrm{d}$ of EPA + DHA ) raised erythrocyte EPA + DHA to about $8 \%$ after 12 weeks, consistent with the observation that this level can be achieved by long-term supplementation with about $1 \mathrm{~g} / \mathrm{d}$ of EPA $+\mathrm{DHA}^{(4)}$. The highest dose may be 
reaching the upper limit for LC $n-3$ PUFA incorporation into erythrocytes. As erythrocyte $n-3$ PUFA levels reflect changes in other tissues, including cardiac cells ${ }^{(3)}$, this could explain the apparent maximum for mortality benefits seen in populations such as Japan which have a high intake of $n-3$ PUFA $^{(27)}$.

High levels of LDL-C and low levels of HDL-C are wellrecognized risk factors for the development of atherosclerosis and $\mathrm{CVD}^{(7,29)}$. There were strong linear relationships between changes in total cholesterol, LDL-C and HDL-C, and increasing dose of fish oil. The literature has not reported consistent findings in relation to the effect of fish oil supplementation on cholesterol. No change has been found in total cholesterol with varying doses of $\operatorname{LC} n-3$ PUFA $^{(8,11,14,30)}$. Fish oil has been reported to increase total HDL- $\mathrm{C}^{(31)}$ or, alternatively, to increase the $\mathrm{HDL}_{2}$ subfraction without increasing total HDL-C ${ }^{(28,32)}$. However, a review of thirty-six crossover and twenty-nine parallel design studies concluded that fish oil supplementation has a minimal effect on HDL-C concentration ${ }^{(33)}$. Others have also found modest and possibly transient elevations of LDL-C following fish oil supplementation ${ }^{(33)}$. While increases in LDL-C are generally associated with an increase in CVD risk $^{(34)}$, fish oil supplementation may have increased LDL particle size which could offset some of the risk associated with elevated LDL-C ${ }^{(28,35,36)}$. Increases in LDL-C particle size after fish oil supplementation have also been negatively correlated with changes in plasma TAG $^{(37)}$. LDL particle size was not measured in the present study, so it is not clear how the increase in LDL-C from fish oil supplementation may influence overall CVD risk and more research is needed into this area.

The linear relationships between dose of DHA and fasting serum lipid concentrations outlined in the present study could be used to predict changes in CVD risk factors which might be expected after consuming diverse sources of DHA for 12 weeks. For every $1 \mathrm{~g} / \mathrm{d}$ increase in DHA intake, the present data would predict a $23 \%$ average reduction in TAG, $4.4 \%$ increase in HDL-C and $7.1 \%$ increase in LDL-C. However, at $0.5 \mathrm{~g} / \mathrm{d}$, the present data predict virtually no effect on LDL-C $(0.2 \%$ reduction), whilst still providing a $13 \%$ reduction in TAG.

A potential application of the work described in the present study would be to predict the effects of consuming DHA-rich foods on blood lipids and possibly other biomarkers of health status based on their ability to increase the proportion of DHA in erythrocytes in healthy subjects over a 6-week period, rather than having to test the effects of consuming foods on individual risk factors in long-term studies with appropriate at-risk subjects, as has previously been the case $\mathrm{c}^{(21,38,39)}$.

\section{Conclusion}

Moderate DHA intakes are related, in a dose-dependent manner, to incorporation of DHA in erythrocytes and changes in blood lipids. The close association between incorporation of DHA in erythrocytes and its effects on serum lipids highlights the importance of erythrocyte DHA as an indicator of cardiovascular health status.

\section{Acknowledgements}

This study was supported by an Australian Research Council linkage grant (LP0561211) in association with Bartlett Grain
Pty. Ltd. and Australian Pork Ltd. Supplement capsules were donated by NuMega Ingredients. The authors would like to thank Amanda Jager for measuring erythrocyte fatty acid composition and blood lipids, and Erin Riley, Alicia Thorp, Tahna Pettman and Keren Kneebone for administrative support. A. M. C., J. D. B. and P. R. C. H. initiated the study. Data were collected by C. M. M., A. M. C. and A. M. H. All authors contributed to analysis and preparation of the manuscript. We declare that we have no conflicts of interest.

\section{References}

1. Brown A, Pang E \& Roberts D (1991) Erythrocyte eicosapentaenoic acid versus docosahexaenoic acid as a marker for fish and fish oil consumption. Prostaglandins Leukot Essent Fatty Acids 44, 103-106.

2. Brown A, Pang E \& Roberts D (1991) Persistent changes in the fatty acid composition of erythrocyte membranes after moderate intake of n-3 polyunsaturated fatty acids: study design implications. Am J Clin Nutr 54, 668-673.

3. Harris WS, Sands SA, Windsor SL, Ali HA, Stevens TL, Magalski A, Porter CB \& Borkon AM (2004) Omega-3 fatty acids in cardiac biopsies from heart transplant patients: correlation with erythrocytes and response to supplementation. Circulation 110, 1645-1649.

4. Harris WS \& von Schacky C (2004) The omega-3 index: a new risk factor for death from coronary heart disease? Prev Med 39, 212-220.

5. Jeppesen J, Hein HO, Suadicani P \& Gyntelberg F (1998) Triglyceride concentration and ischemic heart disease - an eight-year follow-up in the Copenhagen male study. Circulation 97, 1029-1036.

6. Assmann G, Schulte H \& von Eckardstein A (1996) Hypertriglyceridemia and elevated lipoprotein(a) are risk factors for major coronary events in middle-aged men. Am J Cardiol 77, 1179-1184.

7. Szapary PO \& Rader DJ (2004) The triglyceride-high-density lipoprotein axis: an important target of therapy? Am Heart J 148, 211-221.

8. Brown AJ, Roberts DCK, Pritchard JE \& Truswell AS (1990) A mixed Australian fish diet and fish-oil supplementation: impact on the plasma lipid profile of healthy men. Am J Clin Nutr 52, $825-833$.

9. Buckley R, Shewring B, Turner R, Yaqoob P \& Minihane AM (2004) Circulating triacyglycerol and apoE levels in response to EPA and docosahexaenoic acid supplementation in adult human subjects. Br J Nutr 92, 477-483.

10. Geppert J, Kraft V, Demmelmair H \& Koletzko B (2006) Microalgal docosahexaenoic acid decreases plasma triacylglycerol in normolipidaemic vegetarians: a randomised trial. $\mathrm{Br} J$ Nutr 95, 779-786.

11. Howe PRC, Clifton PM \& James MJ (1999) Equal antithrombotic and triglyceride-lowering effectiveness of eicosapentaenoic acid-rich and docosahexaenoic acid-rich fish oil supplements. Lipids 34, S307-S308.

12. Lichtenstein AH, Applel LJ, Brands M, et al. (2006) Diet and lifestyle recommendations revision 2006. A scientific statement from the American Heart Association Nutrition Committee. Circulation 114, 82-96.

13. Rambjor GS, Walen AI, Windsor SL \& Harris WS (1996) Eicosapentaenoic acid is primarily responsible for hypotriglyceridemic effect of fish oil in humans. Lipids 31, S45-S49.

14. Nestel P, Shige H, Pomeroy S, Cehun M, Abbey M \& Raederstorff D (2002) The $n-3$ fatty acids eicosapentaenoic 
acid and docosahexaenoic acid increase systemic arterial compliance in humans. Am J Clin Nutr 76, 326-330.

15. Maki KC, Van Elswyk ME, McCarthy D, Hess SP, Veith PE, Bell M, Subbaiah P \& Davidson MH (2005) Lipid responses to a dietary docosahexaenoic acid supplement in men and women with below average levels of high density lipoprotein cholesterol. J Am Coll Nutr 24, 189-199.

16. Schwellenbach LJ, Olson KL, McConnell KJ, Stolcpart RS, Nash JD \& Merenich JA (2006) The triglyceride-lowering effects of a modest dose of docosahexaenoic acid alone versus in combination with low dose eicosapentaenoic acid in patients with coronary artery disease and elevated triglycerides. $J$ Am Coll Nutr 25, 480-485.

17. Harris WS, Rothrock DW, Fanning A, Inkeles SB, Goodnight SH Jr, Illingworth DR \& Connor WE (1990) Fish oils in hypertriglyceridemia: a dose-response study. Am J Clin Nutr 51, 399-406.

18. Stacpoole PW, Alig J, Ammon L \& Crockett SE (1989) Doseresponse effects of dietary marine oil on carbohydrate and lipid metabolism in normal subjects and patients with hypertriglyceridemia. Metabolism 38, 946-956.

19. Schmidt EB, Varming K, Svaneborg N \& Dyerberg J (1992) $\mathrm{N}-3$ polyunsaturated fatty acid supplementation (pikasol) in men with moderate and severe hypertriglyceridaemia: a doseresponse study. Ann Nutr Metab 36, 283-287.

20. Davidson MH, Maki KC, Kalkowski J, Schaefer EJ, Torri SA \& Drennan KB (1997) Effects of docosahexaenoic acid on serum lipoproteins in patients with combined hyperlipidemia: a randomized, double-blind, placebo-controlled trial. J Am Coll Nutr 16, 236-243.

21. Murphy KJ, Meyer BJ, Mori TA, et al. (2007) Impact of foods enriched with $n$-3 long-chain polyunsaturated fatty acids on erythrocyte $n-3$ levels and cardiovascular risk factors. $\mathrm{Br} J$ Nutr 97, 749-757.

22. Friedewald W, Levy R \& Fredrickson S (1972) Estimation of the concentration of low lipoprotein cholesterol in plasma, without use of the preparative ultracentrifuge. Clin Chem 18, 499-502.

23. Park Y \& Harris WS (2003) Omega-3 fatty acid supplementation accelerates chylomicron triglyceride clearance. J Lipid Res 44, 455-463.

24. Davidson MH (2006) Mechanisms for the hypotriglyceridemic effect of marine omega-3 fatty acids. Am J Cardiol 98, S27-S33.

25. Blonk MC, Bilo HJ, Nauta JJ, Popp-Snijders C, Mulder C \& Donker AJ (1990) Dose-response effects of fish-oil supplementation in healthy volunteers. Am J Clin Nutr 52, 120-127.

26. Nichols P, Virtue P, Mooney B, Elliott N \& Yearsley G (1998) Seafood the Good Food. Canberra: FRDC.
27. Mozaffarian D \& Rimm EB (2006) Fish intake, contaminants and human health. J Am Med Assoc 296, 1885-1899.

28. Mori TA, Burke V, Puddey IB, Watts GF, O'Neal DN, Best JD \& Beilin LJ (2000) Purified eicosapentaenoic and docosahexaenoic acids have differential effects on serum lipids and lipoproteins, LDL particle size, glucose, and insulin in mildly hyperlipidemic men. Am J Clin Nutr 71, 1085-1094.

29. Ross R (1999) Atherosclerosis - an inflammatory disease. $N$ Engl J Med 340, 115-126.

30. Goodfellow J, Bellamy MF, Ramsey MW, Jones CJH \& Lewis MJ (2000) Dietary supplementation with marine omega-3 fatty acids improves systemic large artery endothelial function in subjects with hypercholesterolemia. J Am Coll Cardiol 35, 265-270.

31. Hill A, Buckley J, Murphy K \& Howe P (2007) Combining fish oil supplementation with regular aerobic exercise improves body composition and cardiovascular risk factors. Am J Clin Nutr 85, 1267-1274.

32. Lungershausen YK, Abbey M, Nestel PJ \& Howe PR (1994) Reduction of blood pressure and plasma triglycerides by omega-3 fatty acids in treated hypertensives. $J$ Hypertens 12, $1041-1045$.

33. Harris WS (1997) N-3 fatty acids and serum lipoproteins: human studies. Am J Clin Nutr 65, S1645-S1654.

34. Sharrett A, Ballantyne C, Coady S, Heiss G, Sorlie P, Catellier D \& Patsch W (2001) Coronary heart disease prediction from lipoprotein cholesterol levels, triglycerides, lipoprotein(a), apolipoproteins A-I and B, and HDL density subfractions: the Atherosclerosis Risk in Communities (ARIC) study. Circulation 104, 1108-1113.

35. Meyer BJ, Hammervold T, Rustan AC \& Howe PR (2007) Dose-dependent effects of docosahexaenoic acid supplementation on blood lipids in statin-treated hyperlipidaemic subjects. Lipids 42, 109-115.

36. Kelley DS, Siegel D, Vemuri M \& Mackey BE (2007) Docosahexaenoic acid supplementation improves fasting and postprandial lipid profiles in hypertriglyceridemic men. Am J Clin Nutr 86, 324-333.

37. Suzukawa M, Abbey M, Howe PR \& Nestel PJ (1995) Effects of fish oil fatty acids on low density lipoprotein size, oxidizability, and uptake by macrophages. J Lipid Res 36, 473-484.

38. Howe PR, Downing JA, Grenyer BF, Grigonis-Deane EM \& Bryden WL (2002) Tuna fishmeal as a source of DHA for $n-3$ PUFA enrichment of pork, chicken and eggs. Lipids 37, 1067-1076.

39. Metcalf R, James M, Mantzioris E \& Cleland L (2003) A practical approach to increasing intakes of $n-3$ polyunsaturated fatty acids: use of novel foods enriched with $n-3$ fats. Eur J Clin Nutr 57, 1605-1612. 